\section{Remembering Dr. Wilder Penfield}

I enjoyed reading in the CMAJ about Dr. Blum's encounter with Dr. Wilder Penfield. ${ }^{1}$ I recall first seeing Dr. Penfield in the cafeteria at the Royal Victoria Hospital when I was a medical student (probably around 1970) and being somewhat awed by his presence. I had read The Second Career a few years before, and I also knew him by reputation, through the media.

The memory that stands out most vividly is of attending grand rounds in the amphitheatre of the Montreal Neurological Institute sometime during 1975-1976, when I was a final-year radiology resident. I arrived late, just as the "patient," an elderly man with a protuberant abdomen distending his dressing gown, got up from his wheelchair and began to describe the histology slides of his own untreatable abdominal sarcoma. When I realized that the patient was Dr. Penfield, the enormousness of the moment struck me.

I admire Dr. Blum's maturity and self-confidence as an intern, in having been able to sit down and carry out a personal conversation with Dr. Penfield. Only after several years of medical practice did I reach the point where I became at ease when dealing with famous people and was able to see the common humanity that we all share.

\section{Ian Hammond MD}

Ottawa Hospital, University of Ottawa, Ottawa, Ont.

\section{Reference}

1. Blum A. A bedside conversation with Wilder Penfield. CMAJ 2011;183:745-6.

\section{CMAJ 2011. DOI:10.1503/cmaj.111-2076}

I wish to thank Dr. Blum for the delightful CMAJ article about a visit with Dr. Wilder Penfield. ${ }^{1}$

Now 87, I was a medical student at McGill University and graduated in 1949. I never met Dr. Penfield, but I occasionally watched him operate from behind the glass in the Montreal Neurological Institute, and of course I attended his seminars there as well. I have only one story about the great man and it is this:

It often happened that there was some "visiting fireman" in town who would be asked to join the seminar and to speak to the students. On this occasion the guest was droning on about some topic when he suddenly said, "Isn't that so, Dr. Penfield?" All eyes turned to Dr. Penfield, and there he was, asleep.

I went on to become a general surgeon and well know what a late night in the operating room can do to one's concentration the next day, so I have every sympathy for what may have been a late night for him, too.

\section{David B. Walcott MD}

Retired member, West Vancouver, BC

\section{Reference}

1. Blum A. A bedside conversation with Wilder Penfield. CMAJ 2011;183:745-6.

CMAJ 2011. DOI:10.1503/cmaj.111-2077

\section{Recommendations for stroke: 2010}

The inclusion of dabigatran in the 2010 Canadian guidelines for stroke care, ${ }^{1}$ and more recently in the updated practice guidelines from the American College of Cardiology Foundation, American Heart Association and Heart Rhythm Association, ${ }^{2}$ is important because of the need for an alternative to warfarin for anticoagulation in patients with atrial afibrillation.

In his interesting commentary in $C M A J$, Rudd emphasizes that dabigatran is recommended for patients meeting the inclusion criteria of the RE-LY (Randomized Evaluation of Long term anticoagulant therapY) trial. ${ }^{3}$ Rudd notices that this recommendation is made "despite a lack of data on the long-term safety and efficacy of this drug." The guidelines appear to support the use of dabigatran as an alternative to warfarin without any restrictions. However, we expected a more critical update from the guideline developers on the RE-LY study that would have included some reservations about the use of this molecule.
First, Connolly and colleagues analyze their data under the intention-totreat principle. ${ }^{4,5}$ In this specific case, because the analysis does not take into account the number of dropouts in the patient groups, it overestimates the effects of dabigatran by $4 \%$ to $11 \%$ for embolic or hemorrhagic cerebrovascular or transient ischemic attack. This observation is important given that dropout rates are higher in the groups receiving dabigatran $(21 \%)$ than in those receiving warfarin (16\%). On the contrary, analysis based on the number of patients who completed the study shows some modification of these results: the result for nonspecific ischemia, dabigatran $150 \mathrm{mg}$. warfarin, becomes nonsignificant (rate ratio $[R R] 0.82,95 \%$ confidence interval [CI] 0.64-1.05); the result for myocardial infarction becomes significant in favour of warfarin in comparisons of dabigatran $110 \mathrm{mg}$ v. warfarin (RR 1.44, 95\% CI 1.04-1.99) and dabigatran 150 mg v. warfarin (RR 1.49, 95\% CI 1.072.49); and the result for hospital admissions becomes nonsignificant when comparing dabigatran $110 \mathrm{mg} \mathrm{v}$. warfarin (RR 0.99, 95\% CI 0.95-1.03).

Second, the RE-LY study shows that dabigatran requires an acid environment for absorption; hence, the addition of an acidifying agent is required to allow absorption, and this is what seems to cause dyspepsia and eventually hemorrhage with that molecule. Yet Connolly and colleagues present the results in patients with and without a proton pump inhibitor (PPI). ${ }^{5}$ Analysis of these results shows a marked reduction in the effectiveness of dabigatran $150 \mathrm{mg}$ when taken with a PPI (RR $0.94,95 \%$ CI $0.56-1.58)$. This is a predictable result, given the mechanism of action of PPIs. Thus, a warning should be issued about the use of dabigatran in patients taking a PPI until there are controlled studies that show its effectiveness under this condition. The use of PPIs and any antacids to prevent dyspepsia secondary to dabigatran should also be discouraged.

Out of concern for scientific rigour and to protect patients, we believe a warning about the use of dabigatran should be included in the recommenda- 
tions to be issued in the Canadian practice guidelines on the possibility of substituting this new oral coagulant for warfarin.

Alexandre Ackaoui MD MScA

Jean-Pierre Pellerin PhD

University of Montréal, Montréal, QC

\section{References}

1. Lindsay MP, Gubitz G, Bayley M, et al. Canadian best practice recommendations for stroke care (update 2010). Ottawa (ON): Canadian Stroke Network; 2010.

2. Wann LS, Curtis AB, Ellenbogen KA, et al. 2011 ACCF/AHA/HRS focused update on the management of patients with atrial fibrillation (update on dabigatran): a report of the American College of Cardiology Foundation/American Heart Association Task Force on practice guidelines. Circulation 2011;123:1144-50.

3. Rudd AG. Recommendations for stroke in 2010: a challenging agenda. CMAJ 2011;183:E171-2.

4. Connolly SJ, Ezekowitz MD, Yusuf S, et al. Newly identified events in the RE-LY trial. $N$ Engl $\mathrm{J} \mathrm{Med}$ 2010;363:1875-6.

5. Connolly SJ, Ezekowitz MD, Yusuf S, et al. Dabigatran versus warfarin in patients with atrial fibrillation. N Engl J Med 2009;361:1139-51.

CMAJ 2011. DOI:10.1503/cmaj.111-2075

\section{Measurement of family health teams is underdeveloped}

With regard to the news article by Collier, ${ }^{1}$ innovators use evidence as the launch pad into uncharted territory. When innovations are evaluated, new evidence enables further innovation.

The 2007 Canadian Health Services Research Foundation synthesis report on primary care teams states, "There is high-quality evidence supporting positive outcomes for patients/clients, providers and the system in specialized areas such as interprofessional collaboration in mental health care, and chronic disease prevention and management." ${ }^{2}$ The Ontario Health Quality Council reports that chronic disease affects one in three Ontarians and four out of five seniors. ${ }^{3}$ This is good reason to embark on the interprofessional innovation of family health teams. To date, data from some individual family health teams indicate measurable improvements are taking place. How widespread is this? What's the overall return on investment? We don't know beyond individual case studies.

Measurement is an underdeveloped area in family health teams innovation.
The capacity to measure outcomes and the key processes related to these outcomes is absolutely essential for learning and improvement within a team, for developing the evidence necessary for primary care as a whole and for accountability to the taxpayers who fund the health system.

The Association of Family Health Teams of Ontario is advocating to advance performance measurement across family health teams and to move beyond what the ministry currently mandates (i.e., counting of patient enrolments, numbers of interprofessional health providers, and numbers of patient visits per interprofessional health provider).

\author{
Angie Heydon \\ Executive Director \\ John McDonald \\ President, Association of Family Health \\ Teams of Ontario, Toronto, Ont.
}

CMAJ 2011. DOI:10.1503/cmaj.111-2079

\section{References}

1. Collier R. Verdict still out on family health teams. CMAJ 2011;183:1131-2.

2. Barrett J, Curran V, Glynn L, et al. CHSRF Synthesis: Interprofessional Collaboration and Quality Primary Healthcare. Ottawa (ON): Canadian Health Services Research Foundation; 2007.

3. QMonitor: A report in Ontario's health care system. Toronto (ON): Ontario Health Quality Council; 2007. Available: www.ohqc.ca/pdfs/a3359_qmonitor _fsi_eng1.pdf (accessed 2011 Sept. 9).

Some letters have been abbreviated for print. See www.cmaj.ca for full versions and competing interests.

\section{- Correction \\ Dilating pupils}

In the article "Five things to know about dilating pupils," the second point should read "Pupil dilation is an important therapeutic tool." $C M A J$ regrets any inconvenience this error may have caused.

\section{Reference}

1. Belliveau MJ. Arthur BW. Five things to know about dilating pupils. CMAJ 2011;183:1400.

CMAJ 2011. DOI:10.1503/cmaj.111-2082 